\title{
POR QUE UTILIZAR O FOCO NA FORMA NAS AULAS DE ESPANHOL PARA FALANTES BRASILEIROS?
}

\author{
Why Use a Focus on Form in Spanish Classes Speakers for Brazilians?
}

\author{
Elisa Novaski CORDEIRO, UFPR ${ }^{1}$
}

\begin{abstract}
RESUMO: Este artigo busca justificar a importância do enfoque em questões formais na aula de língua estrangeira, principalmente em se tratando de línguas próximas, como é o caso do português e do espanhol. Quanto maior a proximidade linguística maior será a transferência de estruturas entre a língua estrangeira e a materna, os aprendizes sentem, desse modo, a falsa sensação de que aprender / falar espanhol é fácil, devido à proximidade linguística. Além disso, a abordagem comunicativa entendida de maneira equivocada - enfocando unicamente a produção de significado - pode contribuir para a falsa ideia de que aprender espanhol é fácil. Devido ao enfoque único no sentido, a forma, em geral, é deixada de lado e se prioriza a produção, sem levar em conta a qualidade dessa produção. O estudo da forma pode dar-se através do Foco na Forma, uma maneira diferente de se abordar itens gramaticais em sala de aula. $\mathrm{O}$ trabalho apresenta um aporte teórico sobre o Foco na Forma e foram entrevistadas algumas alunas em relação ao seu posicionamento relativo ao estudo da gramática, a fim de verificar se elas acreditam que o item gramatical pode representar uma ferramenta útil para o desenvolvimento de sua própria proficiência.
\end{abstract}

PALAVRAS CHAVE: foco na forma; ensino de espanhol; abordagem comunicativa

ABSTRACT: This paper seeks to justify the importance of focusing on linguistic forms in the foreign language classroom, especially when dealing with cognate languages, such as Portuguese and Spanish. The greater linguistic proximity transfer structures between the target language and maternal learners feel, thus a false sense that learning / Spanish speaking easy due to the proximity language. Moreover, the communicative approach wrongly understood - only focusing on the production of meaning - can contribute to the misconception that learning Spanish is easy. Due to the unique approach towards the way, in general, is left aside and gives priority to production, without taking into account the quality of this production. The study of the form can take place through Focus on Form, a different way of approaching grammar items in the classroom. The paper presents a theoretical approach on the Focus on Form and some students were interviewed regarding their position on the study of grammar in order to check if they believe the item grammar can be a useful tool for developing their own proficiency.

KEYWORDS: focus on form; Spanish teaching; communicative approach

Quando tratamos do ensino de línguas é praticamente impossível deixar de pensar na influência da língua materna (LM) na produção da língua estrangeira (LE).

\footnotetext{
${ }^{1}$ Mestranda em Letras, Programa de Pós-graduação em Letras, UFPR.
} 
Segundo Henriques (2005), a LM "exerce uma forte influência na produção do aprendiz na língua alvo". Essa influência varia em grau e intensidade de acordo com a proximidade das duas línguas envolvidas. Kellerman (1978) corrobora essa ideia ao definir que a transferência depende da distância entre as línguas implicadas, ou seja, quanto mais próximas as línguas, maior será o grau de transferência.

Desse modo, no caso de línguas muito próximas, como no caso o espanhol e o português, a transferência torna-se inevitável, uma vez que elas são consideradas praticamente variantes dialetais uma da outra, de acordo com ODLIN (1989). Dessa proximidade resulta uma facilidade inicial no aprendizado de espanhol por falantes brasileiros, o que pode gerar uma falsa sensação de facilidade. Desse modo, então, a progressão esperada, muitas vezes, tende a não ocorrer. Alcaraz (2005) e Salinas (2005) definem esse cenário como vantagem no início do processo e desvantagem a seguir.

Temos, portanto, o seguinte ambiente: os aprendizes brasileiros não apresentam dificuldades em comunicar-se na LE, o principal problema é a qualidade desta comunicação. Vidal (2007, p. 172) confirma essa ideia, ao criticar a busca pela mera inteligibilidade:

\begin{abstract}
Antes de qualquer outra coisa, compartilhando a idéia de que não basta apenas entender e ser entendido. Acreditando que 'Me Tarzan. You Jane' não seria suficiente. Acreditando que se possa ir mais além. Acreditando que se precisa ou se deva exigir mais do aprendiz para que ele tenha a oportunidade de atingir um nível de proficiência em uma língua estrangeira, mesmo sendo apenas iniciante, que fosse além da mera inteligibilidade comunicativa. Obviamente, se fosse objetivo do programa a competência comunicativa e o engajamento discursivo.
\end{abstract}

Isto é, não basta primar pela comunicação e esquecer-se da qualidade dessa produção. Uma das origens dessa ênfase unicamente no significado pode estar na compreensão equivocada da abordagem comunicativa (AC). Conforme o pontuado no estudo de Rodrigues (2009), há uma discordância em definir o que seria o estudo de línguas através da $\mathrm{AC}$, tendo em vista que ela vem sendo usada, muitas vezes, como sinônimo de repúdio da forma. O estudo da gramática é concebido, nesses casos, como perda de tempo e ênfase no tradicionalismo. Villalba (2009) também observa essa posição ao afirmar que "a ênfase dada ao significado e não à forma, praticada nos moldes da metodologia comunicativa, não produziu o resultado esperado”, já que os aprendizes não conseguem atingir o avanço esperado.

No caso de LEs tão próximas como o português e o espanhol, o conhecimento do item gramatical se faz muito importante, uma vez que, em várias ocasiões, a diferença principal entre as duas línguas se encontra no nível morfossintático 
(ALCARAZ, 2005). Esse fator cria no aluno, de acordo com Villalba (2009), a necessidade de conhecer o item gramatical, uma vez que ele mesmo percebe que a diferença entre LM e LE está no fator formal.

É fundamental destacar que o problema não está na $\mathrm{AC}$, mas sim na compreensão equivocada dessa abordagem que pode levar-nos a pensar que ela se baseia unicamente na produção do significado, conforme observa Villalba (2008, p. 2):

é comum observar que na prática a palavra chave é 'comunicação', entendendo-se por ela 'ênfase no significado', mesmo que se tratasse de mensagens descontextualizadas ou, na melhor das hipóteses, que acontecem numa situação comunicativa irreal para a comunidade escolar, o que costuma levar à repetição do método audiolingual dos anos 70 .

O principal objetivo da $\mathrm{AC}$, muitas vezes, não é levado em conta: o desenvolvimento da competência comunicativa, definida por Hymes (1972), que prevê o conhecimento de regras gramaticais focadas em situações de uso. Ou seja, Hymes desloca a ênfase única na gramática para relacionar o conhecimento gramatical com o uso da língua. Canale e Swain (1982), por sua vez, afirmam que a competência comunicativa passa pelas competências gramatical, sociolinguística, discursiva e estratégica. Dessa maneira, Mattos e Valerio (2010, p. 136) definem o surgimento da AC como o nascimento de uma nova concepção de língua, que "não mais seria vista como uma estrutura, mas como um meio de se criar significados" (MATTOS e VALERIO, 2010, p. 136). De acordo com esse novo entendimento, o processo de aprendizagem, portanto, implicaria "não no conhecimento de regras gramaticais, mas na capacidade de se fazer uso destas regras com propriedade e eficiência para determinados fins comunicativos". Oliveira (2007) corrobora essa ideia ao afirmar que Hymes amplia o papel do estudo da gramática: graças a ele, o aprendiz adquire a capacidade de produzir e compreender sentenças possíveis gramaticalmente falando. A ênfase, portanto, recai sobre o significado, porém imbricado com o conhecimento formal.

Desse modo, se aceitamos a importância do estudo da forma, cabe perguntar-se como deve ser feito esse estudo em sala de aula? O estudo do item gramatical não significa voltar aos moldes tradicionais, baseados na gramática-tradução, já que, como pontua Silva (2008), o surgimento da AC foi motivado pela insatisfação com o "trabalho repetitivo e mecânico com a oralidade, gramática e tradução", que se baseava mais na capacidade de memorização das regras pelos aprendizes do que no real desenvolvimento da competência comunicativa dos aprendizes. 
Estudos atuais (LONG E ROBINSON, 2003; PINTO, 2010; DINIZ, 2008; SWAIN, 2003; VILLALBA, 2008; 2009 entre outros) têm apontado para o Foco na Forma (do inglês Focus on Form - FonF) como uma alternativa de se estudar a forma de maneira vinculada ao significado. Antes de se definir o que se entende por FonF, é fundamental, estabelecer o que se compreende por gramática. Vidal, 2007 explica que há duas maneiras distintas de se compreender a gramática: sob o olhar do processo e do produto. Se a vemos como produto, levaremos em conta os aspectos morfológicos e sintáticos da língua, isto é, enfocaremos a estrutura da língua. Porém, se o olhar for como processo, a visão é ampliada e passa de um entendimento da língua como meramente estrutural para uma visão mais completa, que abarca aspectos lexicais, fonológicos, semânticos, pragmáticos e discursivos. Essa visão garante, portanto, um entendimento mais completo, que leva em conta a estrutura da língua em contextos de uso. O autor define a gramática, nesta visão, como um "recurso dinâmico que sinaliza significado, aquilo que faz a linguagem ter sentido, o processo de utilização dos recursos da língua para a comunicação da mensagem, partilhamento" (VIDAL, 2007, p. 172). Da mesma maneira, Widdowson, 1990 define a gramática como uma ferramenta para mediar palavras e contextos, ou seja, ela não é compreendida como uma lista de conteúdos e sequências a serem analisados, mas como o resultado da realização do significado através do uso de itens lexicais interligados.

A partir da definição de gramática, podemos definir o que se entende por FonF. Long e Robinson (2003) o caracterizam como um modo de se estudar a gramática não de maneira focada somente em regras e construtos, mas como uma ferramenta capaz de ajudar o aprendiz na evolução da sua competência comunicativa. O FonF compreende a gramática, portanto, como um instrumento de aperfeiçoamento da LE em questão. Segundo os autores, em uma aula baseada no FonF a atenção dos alunos é direcionada a elementos linguísticos que vão aparecendo ao longo da aula, cujo foco primeiro é sempre o significado. Dessa forma, o estudo de elementos linguísticos aparecem para facilitar a comunicação. Pinto (2010, p. 24) complementa essa ideia, pois entende que este enfoque está centralizado no significado com "eventuais incursões nas questões formais da língua desencadeadas por alguma dificuldade de compreensão ou comunicação surgidas durante o processo de interação".

Swain (2003) destaca a importância da reflexão consciente sobre a língua, que leva à metalinguagem sempre de modo contextualizado. Villalba (2009) sinaliza a importância da junção entre o FonF e a interação intergrupal na busca de novos 
conhecimentos e intercâmbio de ideias. Long e Robinson (2003) delimitam esse enfoque entre os dois extremos: puramente explicitação de regras gramaticais e imersão total no idioma, sem qualquer instrução formal.

Portanto, o que se propõe aqui é um modo diferenciado de se abordar a gramática na aula de LE. Primeiro, em relação ao entendimento da gramática, que passa pelo uso da língua, uma vez ela é compreendida como parte integrante da língua e fundamental para a aquisição eficaz de LE. De acordo com Swain (2003), assim como a gramática fora de contexto não é suficiente, só input comunicativo também não é. Sendo assim, faz-se fundamental criar um elo entre o uso e a forma. $\mathrm{O}$ que se pretende, portanto, com o FonF, é propiciar aos aprendizes a oportunidade de discutir sobre o funcionamento da língua alvo. Swain (2003) destaca que os aprendizes devem falar sobre a estrutura da língua, isto é, usar a metalinguagem: usar a língua para falar sobre ela própria. $\mathrm{O}$ ambiente de sala de aula é o espaço de realização de tarefas que façam com que eles reflitam conscientemente sobre a língua, o que promove a produção através da reflexão da forma.

Villalba (2009) sinaliza que esta abordagem não tem relação com o estudo da gramática desvinculada do contexto, como acontecia no método tradicional de gramática-tradução. A diferença principal entre o FonF e o ensino tradicional de gramática é que enquanto este enfoca itens gramaticais sem levar em conta as necessidades do grupo (ELIZI, 2004), aquele é definido como um enfoque no significado com incursões em relação à forma, dependendo das necessidades de determinado grupo de alunos (PINTO, 2010). Assim sendo, Villalba (2009) destaca que o FonF precisa fazer parte das atividades comunicativas dos alunos.

A fim de tentar compreender como os alunos se sentem em relação ao FonF, foi realizado um pequeno questionário com quatro alunas adultas, entre 15 e 20 anos, todas estudantes de um centro de línguas de uma universidade federal ${ }^{2}$. A escolha dessas estudantes aconteceu por vontade própria delas, ou seja, elas mesmas se voluntariaram a participar da pesquisa. As quatro já estudam espanhol regularmente por um semestre e meio e têm idades entre 15 e 20 anos.

\footnotetext{
${ }^{2}$ Os dados foram coletados a partir de minha pesquisa de mestrado, intitulada "Foco na forma na aula de espanhol para falantes brasileiros através da aprendizagem colaborativa" e fazem parte do corpus parcial desta pesquisa, que ainda não foi finalizada.
} 
Elas responderam por escrito algumas perguntas sobre seu posicionamento frente ao estudo de gramática ${ }^{3}$. Seus nomes foram modificados com o objetivo de manter sua identidade preservada.

Uma das perguntas tem o objetivo de verificar o quanto elas se sentem seguras em relação à língua espanhola, isto é, constatar as crenças em relação a uma LE que sabidamente é considerada fácil pela sua semelhança com o português. Uma delas, Isabela, disse sentir-se segura porque afirma que a base de conhecimento que já possui possibilita que ela não sinta receio de se comunicar. Acrescenta ainda que, quanto mais falar, mais erros serão corrigidos, o que levará a um aprendizado maior. Essa visão nos remete às observações de Alcaraz (2005) e Salinas (2005), que discorrem sobre a sensação inicial que os falantes brasileiros têm de que o espanhol é uma língua fácil e não necessita muita dedicação por parte de quem a estuda. A fala da aluna: "com o tempo falando, acabo corrigindo meus erros e aprendendo mais" demonstra que, na sua visão, o processo de aprender espanhol não é uma tarefa muito difícil e, que pode ser facilitada pelo uso da língua simplesmente, sem instruções formais.

As outras três, Giovana, Amanda e Gabriela, por outro lado, não sentem toda esta segurança. Através da análise de suas respostas, é possível inferir que elas têm consciência de que a sua evolução depende mais de sua dedicação do que da simples exposição à língua. Giovana acredita que entende bem quando lê e escuta, mas sua maior dificuldade é na hora de falar. Segundo ela, algumas palavras lhe "fogem" e as estruturas da língua se confundem, assim como na hora de escrever. Ela afirma, no entanto, que se se esforçasse mais fora de sala poderia sentir-se mais segura em relação a estes pontos.

Amanda concorda com a hipótese de que a transferência linguística pode gerar entraves para falantes brasileiros, aprendizes de espanhol, conforme observa Alcaraz (2005). A aluna destaca que, devido à semelhança das duas línguas, ela provavelmente não encontrará problemas para ser compreendida, mas, para ela, isso somente não é suficiente, uma vez que ela quer sentir segurança total quando se comunicar na língua. Essa observação condiz com o apontado por Vidal (2007) sobre o problema da preocupação como a mera inteligibilidade da mensagem. Segundo ele, podemos exigir mais do aluno do que simplesmente entender e ser entendido de maneira truncada e prejudicial ao próprio sucesso da comunicação efetiva.

\footnotetext{
${ }^{3}$ As perguntas do questionário utilizado para coletar os dados se encontram anexadas no final do artigo.
} 
Tanto Amanda como Giovana concordam com o fato de que a proximidade entre LE e LM pode representar um facilitador, mas somente a curto prazo, uma vez que o aperfeiçoamento da LE depende de seu próprio esforço. Giovana, inclusive, afirma que, para ela, a semelhança, em geral, dificulta o aprendizado, já que favorece a confusão de estruturas linguísticas.

Uma das perguntas buscava verificar se as alunas estabeleciam uma relação entre o estudo de gramática e o aperfeiçoamento da LE. Todas elas, com exceção de Giovana, relacionam o estudo de gramática com um aperfeiçoamento do nível de língua, afirmando que, sem ele a progressão pode ser dificultada. Giovana, por outro lado, ressalta que o estudo da gramática é importante, mas que ele deve ser associado ao uso: "Sim, acredito que é bom estudar gramática, mas não como foco principal. Acho que ela deve vir junto com outros temas importantes para aprender a se comunicar na língua, desenvolvendo a fala". Giovana, de maneira empírica, tem em conta que a gramática é importante, mas, ao contrário das outras que a associam ao aperfeiçoamento do nível de língua (Gabriela e Isabela) ou a conjugações e formação de frases (Amanda), ela relaciona gramática e uso, que, de fato, é uma das premissas do FonF. Gil (2002) corrobora essa afirmação, pois acredita que a AC pode ser enriquecida com o estudo de questões formais da língua durante a aprendizagem. Além disso, no FonF a concepção de gramática como processo, conforme definiu Vidal (2007), faz-se pela comunicação e só há sentido em estudar a gramática, uma vez que a entendamos em contextos de uso da língua.

Amanda cita um dado significativo ao falar sobre a relação gramática e aperfeiçoamento do nível de língua. Para ela, estudar gramática é importante: "para as conjugações certas, formação de frase de acordo com a gramática do espanhol, não do português". Alcaraz (2005) discorre sobre o mesmo ao afirmar que o espanhol e o português têm muitas semelhanças e dessemelhanças, estas últimas ocorrendo principalmente no nível sintático da língua. Assim sendo, o estudo da gramática é importante, visto que a necessidade de aprendê-la, muitas vezes, parte do próprio aluno, pois ele mesmo se dá conta de que as diferenças entre as duas línguas encontram-se mais no nível formal (VILLALBA, 2009).

A pergunta seguinte tem o objetivo de verificar se lhes parecem úteis as explicações gramaticais dadas em sala. Todas respondem afirmativamente, mas com justificativas diferentes: Isabela associa as explicações gramaticais com o esclarecimento de dúvidas; Amanda afirma que estas explicações favorecem as 
correções necessárias. Já Gabriela relaciona a explicação com a figura do professor e afirma que esta figura faz com que o aluno preste mais atenção e aprenda melhor o conteúdo. E, por fim, Giovana diz que "alguns esquemas usados para explicar gramática nos ajudam a memorizar mais facilmente as estruturas".

Alguns autores apontam algumas razões para o estudo de gramática para alunos adultos. Salinas (2005) afirma que ele ajuda a evitar os problemas de interferência entre LM e LE e, assim, pode auxiliar na compreensão dos erros. Já Villalba (2009; 2008) e Freitas (2007) pontuam, entre outros fatores, que o conhecimento gramatical gera segurança na hora de comunicar-se, principalmente no caso de línguas próximas. Paiva (2007) afirma que o simples conhecimento de atos de fala, típicos da AC, desvinculados do item gramatical pode não contribuir para a aprendizagem. Desse modo, pode-se verificar que as opiniões das entrevistadas condizem com estas afirmações, uma vez que elas atribuem a importância das explicações gramaticais a diferentes razões: por segurança, por apoio, por verificar diferenças gramaticais entre as LE e LM. Independentemente das razões, elas concordam com a importância da gramática para aperfeiçoar-se.

A próxima questão indagava sobre a eficácia de exercícios estruturais. Duas delas, Isabela e Gabriela, concordam que estes exercícios são importantes, pois "ajudam a fixar os conteúdos" (ISABELA) e por facilitar a aprendizagem de estruturas: "é mais fácil para aprender onde devemos usar cada pronome adequadamente" (GABRIELA), já as outras duas afirmam que esse tipo de "exercício é válido, mas às vezes pode ser repetitivo" (AMANDA) e que eles podem ser bons para revisão, mas "o que ajuda mais é conversação e leitura" (GIOVANA). A observação de Giovana condiz com o FonF, por destacar a importância de ambientes de aprendizado contextualizados seja através da oralidade ou da leitura.

Nos exercícios estruturais a concepção de gramática é a de produto, segundo o definido por Vidal (2007), uma vez que é destacada somente a estrutura da língua. A gramática é, pois, compreendida como um conjunto de regras e construtos que norteiam o funcionamento linguístico. Por essa razão, Isabela e Gabriela afirmam que esse tipo de exercício as ajuda a entender melhor os "conteúdos gramaticais" propriamente ditos. O exercício estrutural parece ser útil neste caso: quando queremos enfocar uma estrutura determinada para fins de memorização. Porém se o estudo da forma se limita somente a esse tipo de exercício, o conhecimento provavelmente não estará disponível quando solicitado na hora da comunicação, o que, segundo Villalba (2009), pode gerar 
frustração por parte de alunos e professores por não encontrar relação entre regras gramaticais e comunicação.

Quando nos restringimos a exercícios estruturais somente, os alunos aprendem a regra gramatical, mas no momento da comunicação sentem dificuldade em utilizá-la. Por essa razão, é importante apresentar as estruturas gramaticais de modo contextualizado em situações de uso da língua, o que pode ser feito através de conversação durante a aula, textos escritos, músicas, ou seja, situações em que a LE esteja realmente sendo utilizada e que o objetivo seja a comunicação e não somente a memorização de dita estrutura comunicativa.

Villalba (2009, p. 102) alerta para o fato de que

\begin{abstract}
é comum observar que os alunos se comunicam por meio de determinadas estruturas memorizadas - que são típicas dos diálogos introdutórios de cada unidade temática no método comunicativo. Em geral, a partir desta prática se introduz a informação gramatical, seguida de uma série de exercícios de corte estruturalista, cujo objetivo é a fixação das novas estruturas.
\end{abstract}

O aluno necessita, portanto, de uma motivação real para produzir a língua e não repetir simplesmente estruturas previamente estudadas e memorizadas. Quando usamos a língua no mundo real, não recortamos estruturas, usamos a língua como um todo com o objetivo de comunicar-nos, seja de maneira oral ou escrita.

Por outro lado, não queremos dizer que o conhecimento da gramática em forma de memorização não é válido. Ele também pode servir como um ponto de apoio quando existe o momento de revisão, como afirmou Giovana. Conejo (2007) observa que um dos problemas das abordagens e metodologias de ensino de LE é a tendência de descartar tudo que havia sido oferecido por metodologias anteriores, deixando de aproveitar as contribuições que essas abordagens poderiam proporcionar. A autora, no entanto, afirma que o professor pode selecionar recursos de diferentes metodologias que atendam às necessidades de seus alunos, dependendo de cada caso específico. Tendo em vista essa liberdade de escolha e reflexão do professor de LE, Conejo (2007) salienta que a $\mathrm{AC}$ auxilia o desenvolvimento da competência comunicativa dos alunos, mas também, em certa medida, os exercícios estruturais e de automatização igualmente podem ser uma ferramenta útil para o desenvolvimento de dita competência:

Uma vez que os alunos não estão em situação ideal de imersão, torna-se difícil fazêlos depreender o funcionamento estrutural da língua de forma implícita. Acreditamos que é muito importante uma exposição explícita dos fatos gramaticais da língua, bem como exercícios para sua sistematização (CONEJO, 2007, p. 1239). 
No caso do espanhol, por exemplo, há estruturas, como a construção da morfologia verbal, que necessitam de um trabalho mais focado na sistematização das formas para sua memorização.

O que se busca, portanto, é uma dosagem entre o estudo da gramática dentro de ambientes que preveem a $\mathrm{AC}$, levando em conta cada grupo de alunos específico. $\mathrm{O}$ FonF se apresenta como uma ferramenta capaz de prestar auxílio nas aulas de LE, principalmente quando há o estudo de duas línguas tão próximas, mas também muito diferentes, como no caso do português e do espanhol.

Uma das questões indagava sobre que tipos de exercícios as entrevistadas consideram ter mais relevância para seu desenvolvimento. Isabela e Amanda afirmam que preferem o trabalho com músicas, já que "o ritmo que a pessoa canta mostra muitas vezes diferentes tipos de falar" (ISABELA). Amanda também afirma que a conversação a ajuda, porém quando ela é "obrigada a só falar espanhol". Gabriela chama a atenção para um ponto semelhante quando cita os textos feitos em dupla na sala de aula. De acordo com ela, este tipo de atividade "além de desenvolver a escrita, também estimula o aluno a conversar em espanhol com seu colega". A mesma opinião é compartilhada por Giovana, pois segundo ela, durante a conversação em sala acontece a "troca de conhecimento, pois quando não sei algo a outra pessoa me ajuda e vice-versa”. Giovana ainda se refere às atividades de leitura como válidas, uma vez que "me fazem entender mais como é a estrutura do idioma".

Para as entrevistadas, os melhores exercícios são os baseados no uso da língua. As músicas, por exemplo, são fruto do uso real da LE, pois são verdadeiros textos autênticos, ou seja, criados não com o objetivo de serem usados para fins didáticos, tal como definido em Lee (1995), apud Schubert (2010, p. 3): "Um texto é considerado autêntico se ele não foi escrito com propósitos pedagógicos (i.e. não para ilustrar pontos específicos de uma língua), mas com um propósito comunicativo da vida real, onde o escritor tem uma determinada mensagem para passar para o leitor". Além disso, as músicas apresentam questões fonético / fonológicas, como variações de sotaque e diferentes usos de entonação relacionada à construção do sentido do discurso. Revelam também questões sociais, culturais e pragmáticas, porque trazem assuntos relevantes para dita comunidade em uma determinada época, bem como apresentam o modo de pensar de determinado grupo social, inclusive questões lexicais, visto que revelam um léxico que, por vezes, é típico de uma região específica. Assim sendo, a música, se for utilizada de maneira adequada em sala de aula, pode representar um aliado em 
atividades com fins pragmáticos e culturais, que podem muito bem ser aliados a questões de ordem formal.

Santos e Pauluk (2007, p. 6) ao enumerar os benefícios do trabalho com música, corroboram as visões acima apresentadas da seguinte maneira:

\begin{abstract}
Além dos aspectos linguísticos como aquisição de vocabulário, compreensão da gramática e expressão oral e escrita, entre outros, podem ser propostos alguns de natureza cultural. As canções como forma de expressão cultural, veiculam valores estéticos, ideológicos, morais, religiosos, etc. Elas possuem, em seus conteúdos, as marcas do tempo e lugar da sua criação.

Ao mesmo tempo, representam um fator cultural importante por expressar a história, o folclore e o idioma de um país/povo, e ainda permite ao professor abordar as quatro habilidades da língua (compreensão, leitura, escrita e fala). É rica em vocabulário, oferece exemplos autênticos de coloquialismo e uma vasta fonte de dados linguístico contemporâneo.
\end{abstract}

A conversação também é citada por três das quatro entrevistadas. A conversação em sala acontece em um ambiente onde o aluno se sinta seguro para expressar seus pontos de vista em relação a diferentes assuntos. Por isso é fundamental que o professor se sensibilize e proponha discussões baseadas em assuntos relevantes para os alunos. O tema deve despertar-lhes interesse para que queiram falar sobre ele, ou seja, ele deve fazer parte da realidade daqueles indivíduos.

A elaboração de texto de modo conjunto, citada por Gabriela, gera episódios de diálogo colaborativo, que se caracteriza por um diálogo construído a fim de realizar determinada tarefa, o que possibilita que o idioma seja aprendido através dele mesmo, do seu próprio uso (LIMA e COSTA, 2010). A entrevistada concorda com essa ideia, uma vez que vê esse tipo de atividade como um estímulo para o uso da LE com o colega.

A opinião de Giovana sobre a troca de conhecimento (o que eu não sei, meu colega me ajuda a construir e vice-versa) durante a conversação é um exemplo da formação de Zona de Desenvolvimento Proximal ${ }^{4}$ durante a aula de LE. O intercâmbio de informações citado pela aluna resulta no crescimento de todo o grupo, através da coconstrução de conhecimento, ocasionada pelo auxílio de um colega para o outro.

E por fim, a visão de Giovana sobre a importância da leitura, vista como um modo de se entender o funcionamento da língua através de textos escritos vem solidificar a ideia de que a gramática precisa ser estudada, mas em contextos de uso que

\footnotetext{
${ }^{4}$ Sobre este assunto, ler VYGOTSKY, Lev S. A formação social da mente. São Paulo: Martins Fontes, 1991.
} 
prevejam a interação, seja entre aluno e aluno, aluno e texto, aluno e livro, aluno e professor.

Cabe, portanto, ao professor perceber quais atividades são mais úteis e funcionam melhor com o seu grupo de alunos. Bem como, dar-se conta de que formas precisam ser enfocadas para otimizar o aproveitamento dos alunos.

\section{CONSIDERAÇÕES FINAIS}

Os comentários feitos pelas alunas nos fazem pensar sobre a importância de se estudar a gramática, mas de uma maneira significativa. Elas admitem que a gramática tem seu lugar dentro do estudo da LE, mas que a aula não deve se restringir somente a ela. A forma é uma ferramenta que possibilita a comunicação de maneira clara e acertada, de modo a evitar possíveis mal entendidos, mas não é o único ponto que deve ser enfocado.

A AC prevê o estudo da forma, de maneira conectada ao sentido. Nesse caso, ambos, forma e sentido, caminham juntos e um depende do outro. Para atender essa necessidade, o professor tem disponível o FonF e pode usá-lo como uma ferramenta a fim de auxiliar seus alunos no desenvolvimento da competência comunicativa.

\section{REFERÊNCIAS BIBLIOGRÁFICAS}

ALCARAZ, Rafael Camorlinga. Do português ao español: os prós e os contras da proximidade. Em: SEDYCIAS, João (Org). O ensino do espanhol no Brasil. São Paulo: Parábola, 2005. Pag 195 - 205.

CANALE, Michael. SWAIN, Merril. Theorical bases of communicative approaches to second language teaching end testing, Applied Linguistics, 1 (1980) p. 1. Disponível em: https://segue.atlas.uiuc.edu/uploads/nppm/CanaleSwain.80.pdf > Acesso em 03/11/2011.

CONEJO, Cássia Rita. O estruturalismo e o ensino de línguas. Em: CELLI - $3^{\circ}$ Colóquio de Estudos Linguísticos e Literários, 2007, Maringá. p. 1233-1244.

DINIZ, Sébora S. S. Fernandes. O diálogo colaborativo como facilitador da aprendizagem de língua estrangeira. Em: Revista Icarahy, n. 3, 2009.

ELIZI, Cesar Eduardo Duarte. Dissertação de mestrado: Foco na forma e present perfect: o efeito da atenção e da conscientização. Campinas, Universidade Estadual de Campinas, 2004. 
FREITAS, Lígia Beskow de. Dissertação de Mestrado: Sobre a fossilização e o papel da atenção no processo de aquisição de inglês como língua estrangeira (um estudo de caso). Pelotas, Universidade Federal de Pelotas, 2007.

GIL, Glória. Desenvolvendo mecanismos de foco na forma através da interação na sala de aula de língua estrangeira. Em: The Especialist, vol. 24, n. 1, pag 35-55. Disponível em: < revistas.pucsp.br/index.php/esp/article/download/9413/6983> Acesso em 08/06/2012.

HENRIQUES, Eunice Ribeiro. Distância entre lenguas e o processo de aprendizagem / aquisição. Em: SEDYCIAS, João (Org). O ensino do espanhol no Brasil. São Paulo: Parábola, 2005. Pag 145 - 171.

HYMES, D. On communicative competence. In PRIDE, J.B.; HOLMES, J. (Eds.) Sociolinguistics. Hardmondsworth, England: Peguin Books, 1972.

KELLERMAN, Eric. Giving learned a break: native lenguage intuitions as a source of predictions about transferability. Em: Working papers in bilingualism. Pag. $60-92$.

LIMA, Marília dos Santos. COSTA, Patrícia da Silva Campelo. Estudos sobre aprendizagem colaborativa em língua estrangeira: relações de pesquisa no contexto brasileiro e canadense. Em: Interfaces Brasil / Canadá, n. 11, 2010. Dsiponível em: < http://www.revistabecan.com.br/arquivos/1277642312.pdf> Acesso em 23/02/2012.

LONG, Michael H. ROBINSON, Peter. Focus on Form: Theory, research and practice. Em: DOUGHTY, Catherine. WILLIAMS, Jessica (Orgs). Focus on form in classroom second language acquisition. Cambridge: CUP, 2003. Pag $15-41$.

MATTOS, Andréa Machado de Almeida. VALÉRIO, Kátia Modesto. Letramento crítico e ensino comunicativo: lacunas e intercessões. Em: Revista brasileira de linguística aplicada, v. 10, n. 1, pag $135-158,2010$.

ODLIN, Terence. Language transfer. Oxford: Oxford University, 1989.

OLIVEIRA, Luciano Amaral. O conceito de competência no ensino de línguas estrangeiras. Em: Stientibus, n. 37, p. 61 - 74, 2007. Disponível em: < http://www2.uefs.br/sitientibus/pdf/37/o_conceito_de_competencia.pdf $>$ Acesso em 08/06/2012.

PAIVA, Vera Lúcia Menezes de Oliveira e. Linguagem, gênero e aprendizagem de língua inglesa. In: ALVAREZ, M. L. O.; SILVA, K. A. Linguística aplicada: múltiplos olhares. Brasília: UNB/ Finatec; Campinas; Pontes Editores, 2007.

PINTO, Edevaldo de Souza. O ensino de língua estrangeira comunicativo com foco na forma. Em: Unar, v. 4, n. 1, p. 22 - 37, 2010. Disponível em: < http://fcla.edu.br/unar2007/revista/volume4/4+PINTO,+Edevaldo+de+Souza.pdf>

Acesso em 23/02/2012.

RODRIGUES, Luiz Carlos Balga. Reflexões sobre a abordagem comunicativa no ensino de francês língua estrangeira: seu apelo sedutor e a ilusão do aprendizado. Em: III Simpósio Internacional de Letras Neolatinas: Navegações e Fronteiras: 
Futurismo e o Surgimento das Vanguardas. 2009. Disponível em: < http://www.letras.ufrj.br/neolatinas/media/publicacoes/cadernos/a9n7/luiz_rodrigues.pd f> Acesso em 08/06/2012.

SALINAS, Arturo. Ensino de espanhol para brasileiros: destacar uso ou forma. Em: SEDYCIAS, João (Org). O ensino do espanhol no Brasil. São Paulo: Parábola, 2005. Pag $54-60$.

SANTOS, Jacinta de Fátima. PAULUK, Ivete. Proposições para o ensino de língua estrangeira por meio de músicas. Em: PARANÁ. Secretaria de Estado da Educação. Superintendência de Educação. O professor PDE e os desafios da escola pública paranaense, 2007. Curitiba: SEED/PR., 2011. V.1. (Cadernos PDE). Disponível em: $<$ http://www.gestaoescolar.diaadia.pr.gov.br/modules/conteudo/conteudo.php?conteudo $=20>$. Acesso em: 12/06/2012. ISBN 978-85-8015-037-7.

SCHUBERT, Bianca Pimentel Berk. A autenticidade do material didático para ensino de inglês como língua estrangeira. Em: Linguagens e diálogos, v. 1, n. 2, p. 1 - 16, 2010 .

SILVA, Ana Paula Correa da. Monografia de graduação: A apropriação de concepções epistemológicas docentes e a implementação de ferramentas tecnológicas no ensino de língua estrangeira: um estudo de caso. Porto Alegre, Universidade Federal do Rio Grande do Sul, 2008.

SWAIN, Merril. The output hypothesis and beyond: Mediating acquisition through collaborative dialogue. Em: LANTOLF, J. (Ed.). Sociocultural theory and second language learning. Oxford: Oxford University Press, 2000.

Focus on Form Through Conscious Reflection. Em: DOUGHTY, Catherine. WILLIAMS, Jessica (Orgs). Focus on form in classroom second Language acquisition. Cambridge: CUP, 2003. Pag $64-81$.

VIDAL, Rejane Teixeira. Ensino - aprendizagem do foco na forma: retorno ou recomeço. Em: The especialist, vol. 28, n. 2, pag 159 - 184, 2007.

VILLALBA, Terumi Koto Bonnet. Foco na Forma na Aquisição de Espanhol por Falantes Brasileiros. Em: Anais do CELSUL, 2008. Disponível em: http://www.celsul.org.br/Encontros/08/enfoque_cognitivista.pdf $>$ Acesso em 03/11/2011.

Uma Pedra no Sapato: Ensino da Gramática no Curso de Espanhol para Universitários Brasileiros. Em: Em aberto, v. 81, pag 99-112, 2009.

WIDDOWSON, H. Aspects of language teaching. Oxford: Oxford University Press, 1990. 


\section{ANEXO}

- Questionário aplicado às alunas.

Pergunta 1: Como você se sente em relação ao uso do espanhol? Você se sente seguro (a)? Por quê?

Pergunta 2: Você acredita que é necessário estudar gramática para melhorar o seu nível de língua? Por quê?

Pergunta 3: Você acredita que as explicações gramaticais dadas em sala são importantes?

Pergunta 4: Você sente que os exercícios estruturais (de preencher lacunas) te ajudam a melhorar no seu espanhol? Por quê?

Pergunta 5: Quais (tipos de) atividades / exercícios (música, leitura, exercícios de preencher lacunas,...) você acredita serem facilitadores no seu desenvolvimento? Por quê? 